\title{
Vitrectomy for diabetic macular edema and the relevance of external limiting membrane
}

Domagoj Ivastinovic ${ }^{*}$, Anton Haas, Martin Weger, Gerald Seidel(D, Christoph Mayer-Xanthaki@D, Ewald Lindner, Andreas Guttmann (1) and Andreas Wedrich (1)

\begin{abstract}
Purpose: To evaluate the relevance of external limiting membrane (ELM) on the visual and morphological results in eyes with diabetic macular edema (DME) that underwent pars plana vitrectomy (PPV) with epiretinal membrane (ERM) and internal limiting membrane (ILM) peeling.

Methods: Medical records of patients with DME who underwent PPV at our unit between January 2017 and December 2019 were reviewed. We assessed preoperative and postoperative best-corrected visual acuity (BCVA), central macular thickness (CMT) using spectral domain OCT (optical coherence tomography). Exclusion criteria were previous PPV; incomplete data; concomitant diseases including retinal vein occlusion, age-related macular degeneration, uveitis; and a follow-up of less than 12 months. The surgeries were performed using 23- or 27-gauge vitrectomy. The ELM was graded depending on its configuration (grade $0=$ intact, grade 1 to 3: disruption of varying extent).

Results: Ninety-nine eyes were enrolled. The postoperative follow up averaged 23.7 months. The preoperative and final BCVA averaged $0.71 \pm 0.28$ and $0.52 \pm 0.3 \log M A R$, respectively $(p=0.002)$. The CMT averaged $515.2 \pm 209.1 \mu \mathrm{m}$ preoperatively and $327 \pm 66.1 \mu \mathrm{m}$ postoperatively $(p=0.001)$. Eyes with intact ELM $(n=8)$ had a significantly better BCVA compared to those with ELM disruption ( $0.28 \pm 0.14$ vs. $0.7 \pm 0.25 \operatorname{logMAR}, p=0.01)$. The final CMT was similar among the groups (intact ELM: $317 \pm 54.6 \mu \mathrm{m}$; ELM disruption: $334 \pm 75.2, p=0.31$ ).

Conclusions: PPV with ERM and ILM peeling is an effective treatment of DME. Eyes with intact ELM preoperatively had a significantly better final visual outcome. To maximize the benefit for patients with DME we recommend early PPV as long as ELM is intact.
\end{abstract}

Keywords: Vitrectomy, Diabetic macular edema, Epiretinal membrane, External limiting membrane, Internal limiting membrane

\section{Introduction}

Diabetic macular edema (DME) is a complication of diabetes and represents one of the leading causes of legal blindness. Characteristic features of DME include an abnormal intra- and eventually sub-retinal fluid

* Correspondence: domagoj.ivastinovic@medunigraz.at

Department of Ophthalmology, Medical University Graz, Auenbruggerplatz 4, 8036 Graz, Austria

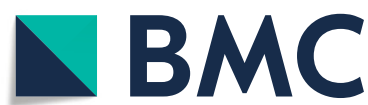

accumulation in the macula secondary to the blood retinal barrier break-down, pericyte loss and endothelial cell junction breakdown [1]. Currently, DME is predominantly treated with intravitreal anti-VEGF or corticosteroid injections [2-5]. The choice of intravitreal agents as first-line treatment in treatment naive patients with DME depends on several factors including the age, lens status, intraocular pressure and recent cardiovascular

(c) The Author(s). 2021, corrected publication 2021. Open Access This article is licensed under a Creative Commons Attribution 4.0 International License, which permits use, sharing, adaptation, distribution and reproduction in any medium or format, as long as you give appropriate credit to the original author(s) and the source, provide a link to the Creative Commons licence, and indicate if changes were made. The images or other third party material in this article are included in the article's Creative Commons licence, unless indicated otherwise in a credit line to the material. If material is not included in the article's Creative Commons licence and your intended use is not permitted by statutory regulation or exceeds the permitted use, you will need to obtain permission directly from the copyright holder. To view a copy of this licence, visit http://creativecommons.org/ licenses/by/4.0/. The Creative Commons Public Domain Dedication waiver (http://creativecommons.org/publicdomain/zero/1. 0/) applies to the data made available in this article, unless otherwise stated in a credit line to the data. 
events. However, specific structural OCT biomarkers may additionally guide the choice of treatment and monitor the therapeutic response [2]. The effectivity of intravitreal treatment can significantly decrease over time, especially in presence of concomitant vitreoretinal interface pathology including traction, thickened vitreous cortex or epiretinal membrane (ERM) [6, 7]. ERMs in particular occur frequently in eyes with DME and play a significant role in the modulation of DME [8-16]. First, the glial cells of ERMs express various cytokines and growth factors including VEGF and thus contribute to the maintenance of DME $[14,15]$. Second, ERMs serve as a mechanical barrier which reduces the permeability of intravitreal anti-VEGF and steroids through the ERM [16].

Pars plana vitrectomy (PPV) combined with ERM peeling is generally an effective treatment in eyes with chronic DME that are refractory to intravitreal injections in terms of visual improvement and decrease of macular thickness [13, 17-23]. However, the postoperative visual outcome varies significantly among eyes depending on the functionality of photoreceptors which is reflected in the configuration of the ellipsoid zone (EZ) and the external limiting membrane (ELM) [23-26]. For example, eyes with intact EZ and ELM commonly show a significantly better postoperative visual outcome than those with disrupted EZ and ELM [23-26]. In order to maximize the benefit for patients with DME and ERM the physicians are thus encouraged to advocate early PPV as long as EZ and ELM are intact. However, before this evidence becomes a decision-making support in the daily routine, its reliability should be tested sufficiently.

The aim of our study is to evaluate whether the ELM configuration had an impact on the long-term postoperative visual and morphological outcome in a routine clinical setting. The focus was set on ELM since its predictive value for visual outcome following PPV in eyes with DME was shown to be slightly superior compared to EZ [23]. The ELM might additionally be more suitable as a preoperative prognostic biomarker since in contrast to EZ the ELM commonly does not restore after PPV $[17,19,23]$.

\section{Methods}

This study was approved by the local ethics committee and adhered to the tenets of the Declaration of Helsinki. We retrospectively reviewed medical records of patients with DME who underwent PPV at the Department of Ophthalmology, Medical University Graz between January 2017 and December 2019. The inclusion criteria were a DME refractory to intravitreal agents due to a visible ERM and a central macular thickness $(\mathrm{CMT})>$ $300 \mu \mathrm{m}$; complete data including preoperative and postoperative best-corrected visual acuity (BCVA), slit lamp examination, indirect ophthalmoscopy and applanation tonometry, optical coherence tomography (OCT); and a postoperative follow up of at least 12 months. Exclusion criteria were previous PPV; incomplete data; insufficient quality of OCT image; signs of concomitant diseases that might be accompanied with macular edema including retinal vein occlusion, age-related macular degeneration, uveitis; and a follow-up of less than 12 months. The number of intravitreal injections prior and after the surgery were also assessed. The patients' records were additionally reviewed for demographic data including age and gender, type and duration of diabetes mellitus, $\mathrm{HbA}_{1 \mathrm{c}}$, stage of diabetic retinopathy and Body-MassIndex calculated as weight/height (in $\mathrm{m})^{2}$.

Spectral domain OCT was conducted with OCT Spectralis version 6.0.9 software (Heidelberg Engineering, Heidelberg, Germany) using volume scanning with 25 sections covering a field of $20 \times 20^{\circ}$ in the macular region. The device used a bandwidth of $297 \mathrm{~nm}$ and a wavelength of $815 \mathrm{~nm}$. Sections were received using the high-speed mode with a resolution of $7 \mu \mathrm{m}$ axially $\times$ $14 \mu \mathrm{m}$ laterally and a distance of $240 \mu \mathrm{m}$ between sections. The CMT was automatically calculated with the built-in software. The ELM was assessed foveally in the area $500 \mu \mathrm{m}$ in either direction from the center of the fovea as previously described [24]. The configuration of ELM was graded from 0 to 3 depending on the extent of ELM disruption, defined as the loss of the line, in the assessed area of $1000 \mu \mathrm{m}$. Accordingly, grade 0 was defined as intact ELM, grade 1 as disruption of ELM in up to one third, grade 2 as disruption of ELM in up to two thirds and grade 3 as complete ELM loss. The grading was performed independently by two experts (D.I. and A.G.). The results of their grading corresponded completely.

All surgeries were performed by the same surgeon (D.I.) using the 23-gauge (Oertli OS4, Berneck, Switzerland) or 27-gauge three-port system (DORC, Zuidland, Netherlands). In all eyes PPV was combined with peeling of both, ERM and internal limiting membrane (ILM). The membranes were stained with ILMBlue $^{\circ}$ and removed with a 27-gauge extended reach wide grip microforceps (both produced by DORC). Triamcinolon (Volon A $10 \mathrm{mg}$, Mibe GmbH, Brehna, Germany) was used to stain the posterior hyaloid where needed. Phacoemulsification with implantation of a monofocal intraocular lens into the capsular bag was combined with PPV in every phakic patient. At the end of the surgery, all patients received $7 \mathrm{mg}$ betamethasone (Diprophos $^{\circ} 1 \mathrm{ml}$ suspension containing $5 \mathrm{mg}$ betamethason as dipropionate and $2 \mathrm{mg}$ bethamethason as disodium pyrophosphate, Merck Sharp \& Dohme $\mathrm{GmbH}$, Vienna, Austria) and $5 \mathrm{mg}$ cefazolin (Kefzol ${ }^{\circ}$, Eli Lilly, Vienna, Austria) in the parabulbar space. 
Postoperatively, the patients were visited on day 1 and dismissed from the hospital depending on the clinical finding. Examinations in the following weeks were performed by the referring ophthalmologist. Each patient was scheduled at our department 1 month after the surgery to perform a complete examination including BCVA measurement, slit lamp examination including indirect ophthalmoscopy and applanation tonometry, and OCT. The intravitreal treatment was continued in case of evident DME. The choice between anti-VEGF and dexamethasone was at physicians' discretion.

The main outcome measures were BCVA and CMT in $\mu \mathrm{m}$ in dependence of ELM configuration. The BCVA was initially measured in Snellen lines and converted in $\log$ MAR to ease the statistical analysis. The descriptive data are presented as the mean \pm standard deviation (range). Normal distribution was assessed with Kolmogorov-Smirnov test before every testing. Depending on distribution, intra-group differences were calculated with paired samples t-test or Wilcoxon-test and inter-group differences with independent $t$-test or Mann Whitney U-test. In case of small sample size, the $p$-value was not calculated. Correlations between various parameters were determined by using Spearman correlation analysis. The statistical analysis was performed using SPSS (IBM, SPSS Statistics 26, New York, USA). The statistics were two-tailed. The threshold for significance was defined as $p<0.05$.

\section{Results}

We enrolled 19 eyes of 17 patients in this study. The mean age of the patients was $69.3 \pm 5$ years $(60-79)$. Four patients (23.5\%) were female and 13 (76.5\%) were male. All patients had diabetes mellitus type 2 . All eyes were treated with repetitive anti-VEGF intravitreal injections prior to surgery. The average number of preoperative anti-VEGF intravitreal injections was $9.4 \pm 6.4$ (3-26) over a period of $26.1 \pm 22$ (3-65) months. Five eyes were additionally treated with $4.0 \pm 2.1(2-7)$ dexamethasone intravitreal injections (Ozurdex ${ }^{\circ}$, Allergan, Ireland) over a period of $28.2 \pm 11.7$ (14-43) months. In 2 eyes a focal laser was performed previously. The postoperative follow up of averaged $23.7 \pm 9.4$ (12-44) months. All eyes showed ERM prior to surgery (Figs. 1 and 2). In 8 eyes (42.1\%) the ELM was intact (grade 0) and in 11 eyes (57.9\%) some degree of ELM disruption was observed (Fig. 1). ELM disruption grade 1 was observed in 4 eyes (21.1\%), grade 2 in 3 eyes (15.8\%) and grade 3 in 4 eyes (21.1\%). Postoperatively, anti-VEGF treatment was continued in 10 eyes and in 2 of these eyes Ozurdex ${ }^{\circ}$ was additionally applied due to reduced effectivity of anti-VEGF. The average number of postoperative anti-VEGF and Ozurdex ${ }^{\circ}$ intravitreal injections was $4.7 \pm 5.7(0-16)$ over $21.6 \pm 10.5(12-44)$ months and $3.0 \pm 2.1(1-6)$ over $25 \pm 9.1$ (13-41) months, respectively. The difference between the preoperative and postoperative number of anti-VEGF injections was statistically significant $(p=0.022)$. The intraocular pressure averaged $14.1 \pm 2.6(10-20) \mathrm{mmHg}$ preoperatively and $14.3 \pm 3(10-21) \mathrm{mmHg}$ at the final visit. We did not observe complications such as endophthalmitis, vitreous hemorrhage or retinal detachment. Table 1 displays the baseline characteristics of enrolled patients depending on the status of ELM.

In general, BCVA averaged $0.71 \pm 0.28(1.1-0.2)$ logMAR preoperatively and $0.52 \pm 0.3(1-0.1) \log$ MAR at the final visit ( $p=0.002$, Wilcoxon test). In 12 eyes phacoemulsification was combined with PPV. In eyes that underwent phacoemulsification BCVA improved by 1.4 Snellen lines and in eyes that already were pseudophakic by 1.3 lines. The CMT averaged $515.2 \pm 209.1$ (3131054) $\mu \mathrm{m}$ preoperatively and $327 \pm 66.1(179-435) \mu \mathrm{m}$ postoperatively ( $p=0.001$, Wilcoxon test). The preoperative and final measures depending on the ELM configuration are displayed in Table 2.

The ELM grading in general strongly correlated with the preoperative BCVA $(r=-0.719, p=0.001)$, and final BCVA $(-0.734, p<0.001)$. A moderate correlation was noted between ELM grading and preoperative CMT $(r=$ $0.576, p=0.01)$. No correlation was observed between ELM grading and the final CMT $(r=0.164, p=0.502)$.

\section{Discussion}

Our study shows that PPV including ERM and ILM peeling generally leads to significant improvement of BCVA and CMT in eyes with nontractional DME with ERM over a mean period of 2 years. The integrity of ELM proved to be a suitable biomarker for visual improvement. Accordingly, eyes with an intact ELM experienced a larger gain in BCVA and had a significantly better final BCVA compared to eyes with ELM disruption (Table 2). In addition, eyes with an intact ELM also had a preoperatively less swelling of the macula compared to those with disrupted ELM. However, no difference was noted in final CMT among eyes with intact or disrupted ELM (Table 2). This finding confirms the evidence that preoperative CMT alone is not predictive for postoperative BCVA improvement $[18,23]$.

So far, numerous biomarkers have been assessed in respect to their predictive value for postoperative outcome in DME $[18,23-28]$. The configuration of ELM and EZ reflect the functionality of photoreceptors and are thus most predictive [23]. ELM is a pseudomembrane formed by adhesions between the inner segments of photoreceptors and Müller cells and EZ represents the density of mitochondria in the inner portions of photoreceptors [29]. In DME, the configuration of ELM proved to slightly better predict the postoperative vision than that 

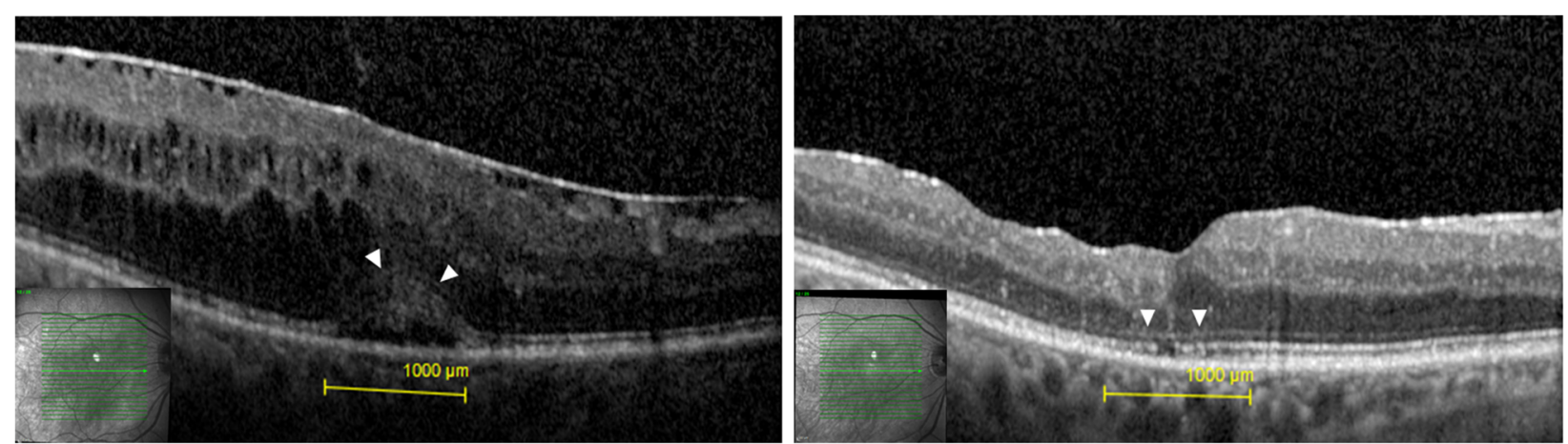

Fig. 1 a Preoperative OCT with an intact external limiting membrane (ELM) (arrowheads). b Postoperative OCT of the same patient 22 months after the surgery. The ELM remained intact (arrowheads). BCVA = best corrected visual acuity, CMT = central macular thickness

of EZ in DME, which could be attributed to the fact that ELM also serves as diffusion barrier between the subretinal space and the inner retina [23, 29]. Consequently, ELM disruption facilitates the migration of proteins, fluid and lipids from the subretinal space into the inner retina and thus contributes to the severity of DME [29]. We are aware that DME is a complex disease and that also other factors including disorganization of retinal inner layers (DRIL) and subretinal fluid (SRF) also contribute to the postoperative outcome [27, 28]. In our study, DRIL was especially observed in eyes with larger extent of ELM disruption (Fig. 1) and eyes with SRF tended to end up with a better BCVA. In advanced DME many morphological retinal changes are present at the same time. The focus of our study, however, was to assess the relevance of ELM alone in eyes that underwent PPV for DME.

PPV was combined with ILM peeling in all eyes. ILM serves as scaffold for ERM and its removal consequently prevents the recurrence of ERM $[18,20,21]$. This aspect is of particular interest in eyes with DME since repetitive intravitreal injections can promote formation of secondary ERM due to upregulation of connective tissue growth factor and fibrosis-related cytokines [6, 30]. In addition, ILM peeling induces some Müller cell injury which consequently promotes a cascade of protective and regenerative reactions including upregulation of the epidermal growth factor receptor and glial fibrillary acidic protein which ultimately results in attenuation of hypoxic damage, reduction of neural cell loss and repair of synapses [31-33]. On the other side, ILM peeling in eyes with DME potentially causes a substantial damage to Müller cell, which can result in macular atrophy, defined as CMT $<220 \mu \mathrm{m}$, in approximately one third of eyes $[18,34,35]$. In our study, we observed macular atrophy in 3 eyes (15.8\%). However, all affected eyes showed ELM disruption grade 3 and large intraretinal cysts prior to surgery (Fig. 1). Hence, macular atrophy presumably occurred because of advanced DME rather than due to ILM peeling alone.

Table 1 Overview of patients' characteristics

\begin{tabular}{|c|c|c|c|}
\hline & Intact ELM $(n=8)$ & Disrupted ELM $(n=11)$ & $P$ value \\
\hline Age in years (range) & $67 \pm 4.2(60-71)$ & $70.9 \pm 5.1(64-79)$ & $0.11^{a}$ \\
\hline $\mathrm{HbA}_{1 c}$ in \% (range) & $6.9 \pm 0.9(5.8-9)$ & $6.8 \pm 0.6(5.8-7.4)$ & $0.73^{\mathrm{a}}$ \\
\hline $\mathrm{BMl}$ in $\mathrm{kg} / \mathrm{m}^{2}$ (range) & $28.9 \pm 3.8(23-33)$ & $28.9 \pm 5.1(21-37)$ & $0.9 \mathrm{~b}$ \\
\hline \multicolumn{4}{|l|}{ Diabetic retinopathy (DR) } \\
\hline Mild & 0 & 1 & \\
\hline Moderate & 2 & 3 & \\
\hline Severe & 3 & 2 & \\
\hline Proliferative & 3 & 5 & \\
\hline Duration of DME until PPV in months & $37.9 \pm 25.3(12-77)$ & $44.9 \pm 26.9(5-94)$ & $0.9 \mathrm{~b}$ \\
\hline \multicolumn{4}{|l|}{ Duration of follow up in months } \\
\hline Preoperative (range) & $30.4 \pm 22.1(6-63)$ & $31.9 \pm 21.6(3-65)$ & $0.88^{\mathrm{a}}$ \\
\hline Postoperative (range) & $19.9 \pm 9.9(12-41)$ & $26.5 \pm 8.4(17-44)$ & $0.15^{\mathrm{a}}$ \\
\hline
\end{tabular}

aindependent t-test

${ }^{\mathrm{b}}$ Mann Whitney U-test 

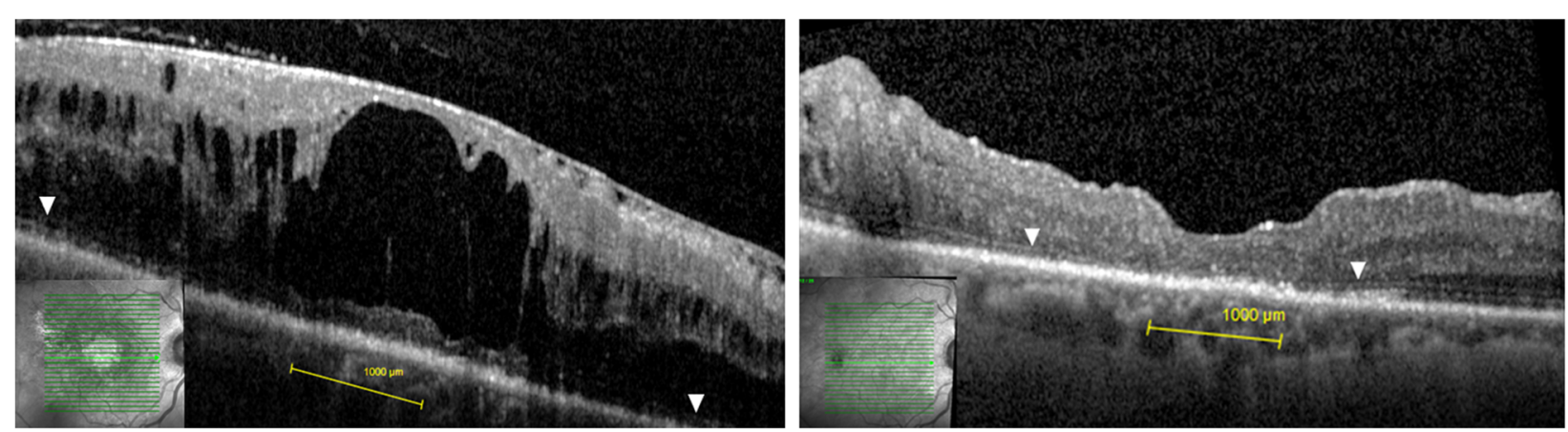

Fig. 2 a. Preoperative OCT with complete external limiting membrane (ELM) disruption (grade 3 ) in the fovea. The arrowheads indicate ELM outside the center. $\mathbf{b}$ Postoperative OCT of the same patient 21 months after the surgery. The ELM remained disrupted in the center. The arrowheads indicate an intact ELM outside the center. BCVA = best corrected visual acuity, CMT=central macular thickness

Our study implicates that PPV should be performed as long as ELM is intact. Therefore, the vitreoretinal interface and the ELM should be carefully observed throughout the treatment with intravitreal injections. In case of ERM formation, PPV with ILM peeling should be performed rather early in order to maximize the benefit for patients. When PPV is used as the last option, the results are commonly disappointing due to compromised microstructure of the macula $[17,23,25]$. Eyes with DME are more likely to develop ERM [8-13]. A recent study even revealed that all eyes with DME show some degree of ERM formation when assessed with electron microscopy and immunohistochemistry, even when no ERM was detectable on OCT. [13] Recently, PPV was even used as first-line option in eyes with treatment naïve DME without evident ERM [18]. This study showed that shorter duration from DME diagnosis to PPV is crucial to achieve a satisfactory visual outcome [18]. In eyes with long lasting DME the visual results were less satisfactory due to the outer retinal damage [18]. Interestingly, in the latter study none of the enrolled eyes $(n=120)$ required intravitreal injections or macula laser after PPV over a period of 2 years [18]. Contrary to these results, we discontinued intravitreal injections in only 5 eyes (26.3\%) due to anticipated ineffectiveness based on microstructural macular damage. The number of anti-VEGF injections received after PPV was significantly lower. However, we did not exactly evaluate the impact of postoperative intravitreal injections on the final outcome since this would be beyond the scope of this study. Based on our experience we assume that the majority of eyes would still require intravitreal injections after PPV, however in a lower number than preoperatively.

Early PPV offers additional benefits in eyes with DME. For example, PPV leads to hyperoxygenation of the vitreous cavity and thus increases the oxygen supply to the retina and additionally decreases the level of oxidative stress [36, 37]. This is of particular interest since the oxygen tension in the vitreous of diabetic patients is significantly lower than in nondiabetic controls, even if panretinal laser photocoagulation was performed previously [38]. Moreover, vitrectomized eyes additionally show approximately 2000 times lower viscosity of the vitreous cavity, which facilitates the clearance of VEGF and cytokines from the retina into the vitreous cavity and thus additionally contributes to the resolution of DME $[33,39,40]$. However, it should be considered that

Table 2 Preoperative and postoperative results depending on the ELM status

\begin{tabular}{llll}
\hline & Intact ELM $(\boldsymbol{n}=\mathbf{8})$ & Disrupted ELM $(\boldsymbol{n}=\mathbf{1 1})$ & $\boldsymbol{P}$ value \\
\hline $\begin{array}{l}\text { BCVA in logMAR } \\
\text { Preoperative }\end{array}$ & $0.49 \pm 0.26(1-0.2)$ & $0.86 \pm 0.16(1.1-0.7)$ & $0.004^{\mathrm{b}}$ \\
$\begin{array}{l}\text { Postoperative } \\
\text { P value }\end{array}$ & $0.28 \pm 0.14(0.5-0.1)$ & $0.7 \pm 0.25(1-0.3)$ & $0.01^{\mathrm{b}}$ \\
CMT in $\mu \mathrm{m}$ & $0.041^{c}$ & $0.017^{c}$ & \\
Preoperative & & $607.6 \pm 231.9(364-1054)$ & $0.005^{\mathrm{b}}$ \\
Postoperative & $388.1 \pm 60.7(313-486)$ & $334.3 \pm 75.2(179-435)$ & $0.31^{\mathrm{b}}$ \\
P value & $317 \pm 54.6(260-429)$ & $0.003^{c}$ & \\
\hline
\end{tabular}

independent t-test

${ }^{b}$ Mann Whitney U-test

cWilcoxon test 
hyperoxygenation after PPV can cause oxidative stress and reduce the outflow capacity of the trabecular meshwork and consequently cause ocular hypertension or even glaucoma in up to $6.3 \%$ [41]. In addition, retinal detachment occurs after PPV in $4.3 \%$ of eyes in diabetic patients [42]. In our study we did not observe any case with ocular hypertension or retinal detachment.

Our study has several limitations including its retrospective design and a low number of eyes. These facts certainly reduce the validity of our study. The limited power of our study additionally compromised the assessment of valid odds ratios for various factors for the BCVA improvement of $\geq 2$ Snellen lines. In this regard a regression analysis, for example, revealed an odds ratio for ELM disruption (grade 1 to 3 ) of 2.11; however, the $95 \%$ confidence interval ranged widely between 0.32 and 13.9 and it was not statistically significant $(p=0.44)$. Despite the limited number of eyes, our study clearly identified the predictive value of ELM in eyes that underwent PPV for DME. In addition, the statistical power was sufficient to show statistical significance in the main parameters including BCVA, CMT and its correlation with ELM grading. Moreover, the study reflects a real-life setting, which is valuable for the clinical routine and the mean follow up of approximately 2 years (median 21 months), is comparably long. However, although PPV with ILM peeling generally showed to be beneficial over the observed period of approximately 2 years, we cannot exclude a development of macula atrophy with consecutive vision decline secondary to the ILM peeling in the following years.

In conclusion, PPV with ILM peeling is beneficial in eyes with DME in functional and anatomical regard. The configuration of ELM proved to be a good predictive biomarker. Therefore, we advocate early PPV in eyes with DME and ERM resistant to intravitreal treatment as long as the ELM is intact.

\section{Abbreviations \\ Anti-VEGF: Anti-vascular endothelial growth factor; BCVA: Best-corrected visual acuity; CMT: Central macular thickness; DME: Diabetic macular edema; DRIL: Disorganization of retinal inner layers; ELM: External limiting membrane; ERM: Epiretinal membrane; EZ: Ellipsoid zone; ILM: Internal limiting membrane; OCT: Optical coherence tomography; PPV: Pars plana vitrectomy; SRF: Subretinal fluid}

\section{Acknowledgements}

Not applicable.

\section{Authors'contributions}

DI: draft and design of the work, interpretation of data, AH: substantively revision. MW: substantively revision. GS: substantively revision. CMX: substantively revision. EL: substantively revision. AG: interpretation of data, substantively revision. AW: substantively revision. The author(s) read and approved the final manuscript.

Code availability

Not applicable.

\section{Funding}

This research did not receive any specific grant from funding agencies in the public, commercial, or not-for-profit sectors.

\section{Availability of data and materials}

The datasets generated and/or analyzed during the current study are not publicly available but are available from the corresponding author on reasonable request.

\section{Declarations}

\section{Ethics approval and consent to participate}

This study was performed in line with the principles of the Declaration of Helsinki. Approval was granted by the Ethics Committee of the Medical University Graz (Date: 30.11.2020/No.: 33-042 ex 20/21).

\section{Consent for publication}

Not applicable.

\section{Competing interests}

None of the authors have any conflicts of interest or financial disclosures in this study.

Received: 12 May 2021 Accepted: 1 September 2021

Published online: 15 September 2021

\section{References}

1. Ceravolo I, Oliverio GW, Alibrandi A, Bhatti A, Trombetta L, Rejdak R, et al. The application of structural retinal biomarkers to evaluate the effect of intravitreal Ranibizumab and dexamethasone intravitreal implant on treatment of diabetic macular edema. Diagnostics. 2020;10(6). https://doi. org/10.3390/DIAGNOSTICS10060413.

2. Pietras-Baczewska A, Nowomiejska K, Brzozowska A, Toro MD, Załuska W, Sztanke M, et al. Antioxidant Status in the Vitreous of Eyes with Rhegmatogenous Retinal Detachment with and without Proliferative Vitreoretinopathy, Macular Hole and Epiretinal Membrane. Life. 2021;11(5). https://doi.org/10.3390/LIFE11050453.

3. Boyer DS, Yoon YH, Belfort R, Bandello F, Maturi RK, Augustin AJ, et al. Three-year, randomized, sham-controlled trial of dexamethasone intravitreal implant in patients with diabetic macular edema. Ophthalmology. 2014; 121(10):1904-14. https://doi.org/10.1016/j.ophtha.2014.04.024.

4. Brown DM, Schmidt-Erfurth U, Do DV, Holz FG, Boyer DS, Midena E, et al. Intravitreal aflibercept for diabetic macular edema: 100-week results from the VISTA and VIVID studies. Ophthalmology. 2015;122:2044-52. https://doi. org/10.1016/j.ophtha.2015.06.017

5. Mitchell $P$, Wong TY. Management paradigms for diabetic macular edema. Am J Ophthalmol. 2014;157(3):505-513.e8. https://doi.org/10.1016/j.ajo.2 013.11.012.

6. Kang YK, Park HS, Park DH, Shin JP. Incidence and treatment outcomes of secondary epiretinal membrane following intravitreal injection for diabetic macular edema. Sci Rep. 2020;10:1-7.

7. Kulikov AN, Sosnovskii SV, Berezin RD, Maltsev DS, Oskanov DH, Gribanov NA. Vitreoretinal interface abnormalities in diabetic macular edema and effectiveness of anti-VEGF therapy: an optical coherence tomography study. Clin Ophthalmol. 2017;11:1995-2002. https://doi.org/10.2147/OPTH.S146019.

8. Ghazi NG, Ciralsky JB, Shah SM, Campochiaro PA, Haller JA. Optical coherence tomography findings in persistent diabetic macular edema: the vitreomacular interface. Am J Ophthalmol. 2007:144:747-754.e2.

9. Kim BY, Smith SD, Kaiser PK. Optical coherence tomographic patterns of diabetic macular edema. Am J Ophthalmol. 2006;142(3):405-412.e1. https:// doi.org/10.1016/j.ajo.2006.04.023.

10. Wong Y, Steel DHW, Habib MS, Stubbing-Moore A, Bajwa D, Avery PJ. Vitreoretinal interface abnormalities in patients treatedwith ranibizumab for diabetic macular oedema. Graefes Arch Clin Exp Ophthalmol. 2017;255(4): 733-42. https://doi.org/10.1007/s00417-016-3562-0.

11. Akbar Khan I, Mohamed MD, Mann SS, Hysi PG, Laidlaw DA. Prevalence of vitreomacular interface abnormalities on spectral domain optical coherence tomography of patients undergoing macular photocoagulation for Centre involving diabetic macular oedema. Br J Ophthalmol. 2015;99(8):1078-81. https://doi.org/10.1136/bjophthalmol-2014-305966. 
12. Ophir A, Martinez MR, Mosqueda P, Trevino A. Vitreous traction and epiretinal membranes in diabetic macular oedema using spectral-domain optical coherence tomography. Eye. 2010;24(10):1545-53. https://doi.org/1 0.1038/eye.2010.80.

13. Hagenau F, Vogt D, Ziada J, Guenther SR, Haritoglou C, Wolf A, et al. Vitrectomy for diabetic macular edema: optical coherence tomography criteria and pathology of the Vitreomacular Interface. Am J Ophthalmol. 2019;200:34-46. https://doi.org/10.1016/j.ajo.2018.12.004.

14. Harada C, Mitamura Y, Harada T. The role of cytokines and trophic factors in epiretinal membranes: involvement of signal transduction in glial cells. Prog Retin Eye Res. 2006;25(2):149-64. https://doi.org/10.1016/j.preteyeres.2005.09. 001.

15. Chen YS, Hackett SF, Schoenfeld CL, Vinores MA, Vinores SA, Campochiaro PA. Localisation of vascular endothelial growth factor and its receptors to cells of vascular and avascular epiretinal membranes. Br J Ophthalmol. 1997; 81(10):919-26. https://doi.org/10.1136/bjo.81.10.919.

16. Namba R, Kaneko H, Suzumura A, Shimizu H, Kataoka K, Takayama K, et al. In vitro epiretinal membrane model and antibody permeability: relationship with anti-VEGF resistance in diabetic macular edema. Investig Ophthalmol Vis Sci. 2019;60(8):2942-9. https://doi.org/10.1167/iovs.19-26788.

17. Uji A, Murakami T, Suzuma K, Yoshitake S, Arichika S, Ghashut R, et al. Influence of vitrectomy surgery on the integrity of outer retinal layers in diabetic macular edema. Retina. 2018;38(1):163-72. https://doi.org/10.1097/ IAE.0000000000001519.

18. Iglicki M, Lavaque A, Ozimek M, Negri HP, Okada M, Chhablani J, et al. Biomarkers and predictors for functional and anatomic outcomes for small gauge pars plana vitrectomy and peeling of the internal limiting membrane in naïve diabetic macular edema: the VITAL study. PLoS One. 2018;13(7): e0200365. https://doi.org/10.1371/journal.pone.0200365.

19. Miyamoto $\mathrm{N}$, Ishida $\mathrm{K}$, Kurimoto $\mathrm{Y}$. Restoration of photoreceptor outer segments up to 24 months after pars Plana vitrectomy in patients with diabetic macular edema. Ophthalmol Retina. 2017;1(5):389-94. https://doi. org/10.1016/j.oret.2017.01.017.

20. Kumagai $K$, Hangai M, Ogino N, Larson E. Effect of internal limiting membrane peeling on long-term visual outcomes for diabetic macular edema. Retina. 2015;35(7):1422-8. https://doi.org/10.1097/IAE. 0000000000000497.

21. Bonnin S, Sandali O, Bonnel S, Monin C, El Sanharawi M. Vitrectomy with internal limiting membrane peeling for tractional and nontractional diabetic macular EDEMA: long-term results of a comparative study. Retina. 2015; 35(5):921-8. https://doi.org/10.1097//AE.0000000000000433.

22. Harbour JW, Smiddy WE, Flynn HW, Rubsamen PE. Vitrectomy for diabetic macular edema associated with a thickened and taut posterior hyaloid membrane. Am J Ophthalmol. 1996;121(4):405-13. https://doi.org/10.1016/ S0002-9394(14)70437-4.

23. Chhablani JK, Kim JS, Cheng L, Kozak I, Freeman W. External limiting membrane as a predictor of visual improvement in diabetic macular edema after pars plana vitrectomy. Graefes Arch Clin Exp Ophthalmol. 2012;250(10): 1415-20. https://doi.org/10.1007/s00417-012-1968-x.

24. Maheshwary AS, Oster SF, Yuson RMS, Cheng L, Mojana F, Freeman WR. The association between percent disruption of the photoreceptor inner segment-outer segment junction and visual acuity in diabetic macular edema. Am J Ophthalmol. 2010;150(1):63-67.e1. https://doi.org/10.1016/j.a jo.2010.01.039

25. Otani T, Yamaguchi Y, Kishi S. Correlation between visual acuity and foveal microstructural changes in diabetic macular edema. Retina. 2010;30(5):77480. https://doi.org/10.1097//AE.0b013e3181c2e0d6.

26. Otani T, Kishi S. A controlled study of vitrectomy for diabetic macular edema. Am J Ophthalmol. 2002;134(2):214-9. https://doi.org/10.1016/S00029394(02)01548-9.

27. Sun JK, Lin MM, Lammer J, Prager S, Sarangi R, Silva PS, et al. Disorganization of the retinal inner layers as a predictor of visual acuity in eyes with center-involved diabetic macular edema. JAMA Ophthalmol. 2014; 132(11):1309-16. https://doi.org/10.1001/jamaophthalmol.2014.2350.

28. Ichiyama Y, Sawada O, Mori T, Fujikawa M, Kawamura H, Ohji M. The effectiveness of vitrectomy for diffuse diabetic macular edema may depend on its preoperative optical coherence tomography pattern. Graefes Arch Clin Exp Ophthalmol. 2016;254(8):1545-51. https://doi.org/10.1007/s00417015-3251-4.
29. Bunt-Milam AH, Saari JC, Klock IB, Garwin GG. Zonulae adherentes pore size in the external limiting membrane of the rabbit retina. Investig Ophthalmol Vis Sci. 1985;26(10):1377-80.

30. Zhang Q, Qi Y, Chen L, Shi X, Bai Y, Huang L, et al. The relationship between anti-vascular endothelial growth factor and fibrosis in proliferative retinopathy: clinical and laboratory evidence. Br J Ophthalmol. 2016;100(10): 1443-50. https://doi.org/10.1136/bjophthalmol-2015-308199.

31. Lewis GP, Fisher SK. Up-regulation of glial fibrillary acidic protein in response to retinal injury: its potential role in glial remodeling and a comparison to vimentin expression. Int Rev Cytol. 2003;230:263-90. https:// doi.org/10.1016/S0074-7696(03)30005-1.

32. Unterlauft JD, Eichler W, Kuhne K, Mei Yang X, Yafai Y, Wiedemann P, et al. Pigment epithelium-derived factor released by mü ller glial cells exerts neuroprotective effects on retinal ganglion cells. Neurochem Res. 2012; 37(7):1524-33. https://doi.org/10.1007/s11064-012-0747-8.

33. Wang M, Ma W, Zhao L, Fariss RN, Wong WT. Adaptive Müller cell responses to microglial activation mediate neuroprotection and coordinate inflammation in the retina. J Neuroinflammation. 2011;8(1):173. https://doi. org/10.1186/1742-2094-8-173.

34. Romano MR, Romano V, Vallejo-Garcia JL, Vinciguerra R, Romano M, Cereda $M$, et al. Macular hypotrophy after internal limiting membrane removal for diabetic macular edema. Retina. 2014;34(6):1182-9. https://doi.org/10.1097/ IAE.0000000000000076.

35. Yoshikawa M, Murakami T, Nishijima K, Uji A, Ogino K, Horii T, et al. Macular migration toward the optic disc after inner limiting membrane peeling for diabetic macular edema. Investig Ophthalmol Vis Sci. 2013;54(1):629-35. https://doi.org/10.1167/iovs.12-10907.

36. Stefánsson E. Physiology of vitreous surgery. Graefes Arch Clin Exp Ophthalmol. 2009;247(2):147-63. https://doi.org/10.1007/s00417-008-0980-7.

37. Holekamp NM, Shui YB, Beebe DC. Vitrectomy surgery increases oxygen exposure to the lens: a possible mechanism for nuclear cataract formation. Am J Ophthalmol. 2005;139(2):302-10. https://doi.org/10.1016/j.ajo.2004.09. 046.

38. Holekamp NM, Shui YB, Beebe D. Lower intraocular oxygen tension in diabetic patients: possible contribution to decreased incidence of nuclear sclerotic cataract. Am J Ophthalmol. 2006;141(6):1027-32. https://doi.org/1 0.1016/j.ajo.2006.01.016.

39. Lee SS, Ghosn C, Yu Z, Zacharias LC, Kao H, Lanni C, et al. Vitreous VEGF clearance is increased after vitrectomy. Investig Ophthalmol Vis Sci. 2010; 51(4):2135-8. https://doi.org/10.1167/iovs.09-3582.

40. Wolf S, Schnurbusch U, Wiedemann P, Grosche J, Reichenbach A, Wolburg $H$. Peeling of the basal membrane in the human retina: ultrastructural effects. Ophthalmology. 2004;111(2):238-43. https://doi.org/10.1016/j. ophtha.2003.05.022.

41. Ivastinovic D, Smiddy WE, Wackernagel W, Palkovits S, Predović J, Šarić B, et al. The occurrence of delayed ocular hypertension and glaucoma after pars plana vitrectomy for rhegmatogenous retinal detachment. Acta Ophthalmol. 2016;94(6):e525-7. https://doi.org/10.1111/aos.12925.

42. Schrey S, Krepler K, Wedrich A. Incidence of rhegmatogenous retinal detachment after vitrectomy in eyes of diabetic patients. Retina. 2006;26(2): 149-52. https://doi.org/10.1097/00006982-200602000-00004.

\section{Publisher's Note}

Springer Nature remains neutral with regard to jurisdictional claims in published maps and institutional affiliations.

Ready to submit your research? Choose BMC and benefit from:

- fast, convenient online submission

- thorough peer review by experienced researchers in your field

- rapid publication on acceptance

- support for research data, including large and complex data types

- gold Open Access which fosters wider collaboration and increased citations

- maximum visibility for your research: over $100 \mathrm{M}$ website views per year

At BMC, research is always in progress.

Learn more biomedcentral.com/submission 